\title{
A Rare Case of Ventricular Rupture and Aortic Endocarditis Due to SARS-COV-2 Treated By 2 Step Cardiac Surgery
}

\author{
Giuseppe Nasso ${ }^{1 *}$, Nicola Di Bari ${ }^{1}$, Raffaele Bonifazi ${ }^{1}$, Marco Moscarelli ${ }^{1}$, Giuseppe Santarpino ${ }^{1,2}$ \\ and Giuseppe Speziale ${ }^{1}$ \\ ${ }^{1}$ Department of Cardiovascular Surgery, Anthea Hospital, GVM Care\&Research, Italy \\ ${ }^{2}$ Department of Cardiac Surgery, Paracelsus Medical University, Germany \\ *Corresponding author: Giuseppe Nasso, GVM Care and Research, Anthea Hospital Via Camillo Rosalba, 35/38 Bari, Italy
}

\section{ARTICLE INFO}

Received: October 18, 2021

Published: 慧 October 28, 2021

Citation: Giuseppe Nasso, Nicola Di Bari, Raffaele Bonifazi, Marco Moscarelli, Giuseppe Santarpino, et al., A Rare Case of Ventricular Rupture and Aortic Endocarditis Due to SARS-COV-2 Treated By 2 Step Cardiac Surgery. Biomed J Sci \& Tech Res 39(4)-2021. BJSTR. MS.ID.006337.

\section{ABSTRACT}

We describe an alternative procedure to treat the patient underwent aortic valve replacement with lesion of the right ventricle caused by tenacious mediastinalepicardial adhesions COVID-19 related. This alternative procedure is performed in two steps. In the first step is useful only to repair the right ventricle and in the second step, after 10 days, to proceed with aortic valve replacement/repair. This is important to avoid clamping the aorta which can cause ischemia of the repaired tissue, long CEC times with additional risk for the patient and to allow the stabilization of the patient in intensive care.

Keywords: COVID-19; SARS-COV-2; Pericardial Patch; Right Ventricle Injury

\section{Introduction}

Although SARS-CoV-2 infection primarily targets the respiratory system [1,2], cardiac complication is the most common comorbidity. Several studies from China reported acute cardiac injury in $7.2 \%$ to $27.8 \%$ among hospitalized patients [3-5]. Some of the cardiovascular complications of COVI- 19 include STelevation myocardial infarction [6], myocarditis [7], cardiogenic shock, arrhythmias, pericardial effusions, cardiac tamponade [8] and infective endocarditis [9]. We report the case of a patient who developed COVID-19 endocarditis and myocarditis with the development of tenacious mediastinal-epicardial adhesions responsible for injury to the right ventricle treated with pericardial patch in two steps.

\section{Case Presentation}

Informed consent was obtained by the patient. Consent from the institutional review board was waived, being a clinical case. A 46-year-old male was referred to our hospital with progressive shortening of breath of recent onset. Transthoracic echocardiography revealed bicuspid aortic valve with moderate insufficiency and ascending aortic aneurysm with a maximum diameter of $55 \mathrm{~mm}$. No coronary artery disease was found at the angiogram. The patient underwent replacement of the ascending aortic with aortic valve repair (subcommisural annuloplasty). The postoperative course was uneventful and the patient was discharged home. Transthoracic echocardiography showed ejection fraction of $55 \%$ and mild aortic valvular insufficiency. After a day the patient performed COVID-19 molecular swab test resulted positive with mild symptoms: fever $\left(37.5^{\circ} \mathrm{C}\right)$, mild dyspnea, changes in taste. Two months later the patient was readmitted because of progressive dyspnea (NYHA class III). Transthoracic echocardiogram showed severe aortic valve insufficiency. Transesophageal echocardiogram confirmed severe aortic valve insufficiency with prolapse of the non-coronary cusp and vegetation on both cusps. 


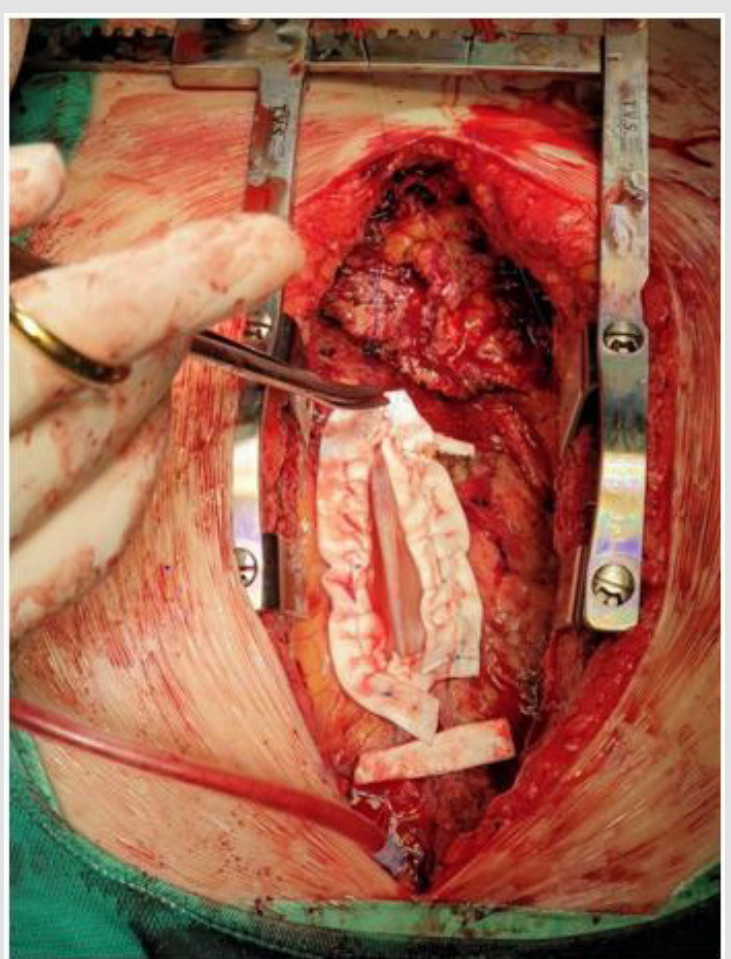

Figure 1: Right Ventricular reconstruction without cross clamp, in cardiopulmonary bypass.

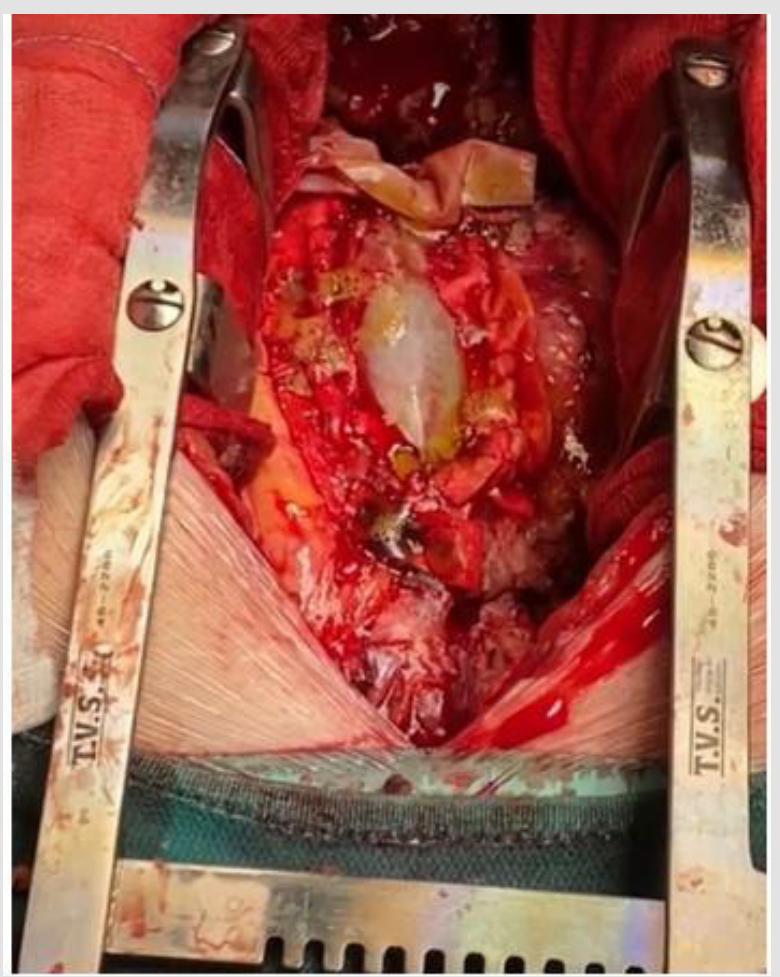

Figure 2: Results of right ventricular repair at the time of delay surgical treatment of aortic valve replacement after 10 days.
The patient was referred for redo surgery of aortic valve replacement with mechanical prosthesis. At reoperation, the approach was through median sternotomy after cardiopulmonary bypass instituted by cannulation of the right femoral artery and vein. The surgery was complicated in the first phase by laceration of the right ventricle due to very tenacious mediastinal-epicardial adhesions from pericarditis caused by COVID-19. The patient underwent repair of the right ventricle with bovine pericardium patch (Figures 1 \& 2). After discussion in heart team (cardiac surgeon, cardiologist and cardioanesthesiologist) it was decided to postpone the aortic valve replacement. The patient was transferred to intensive care. Ten days later the patient underwent aortic valve replacement with mechanical prosthesis (Sorin Bicarbon $25 \mathrm{~mm}$ ). The postoperative course was uneventful and the patient was discharged home in NYHA class I. Transthoracic echocardiography showed ejection fraction of $45 \%$. After one year the patient was in NYHA class I with aortic prosthesis in place without periprosthetic leaks and vegetations.

\section{Conclusion}

This is a rare case reported in the literature of endocarditis and myocarditis caused by COVID-19 characterized by very tenacious mediastinal-epicardial adhesions. More attention is needed during the reopening of patients with previous COVID-19 because, despite the start of CEC and the empting of the right cardiac section, the risk of injury of the right ventricle is very high. When it happens, we suggest to proceed in two steps. In the first step is useful only to repair the right ventricle and in the second step, after 10 days, to proceed with aortic valve replacement/repair. This is important to avoid clamping the aorta which can cause ischemia of the repaired tissue, long CEC times with additional risk for the patient. In conclusion the message to take home is not to underestimate the tenacious adhesions from CVID-19 related myocarditis and, in case of laceration of the right ventricle, proceed in two steps to allow the stabilization of the patient in intensive care.

\section{References}

1. Canatan D, Vives Corrons JL, De Sanctis V (2020) The multifacets of COVID-19 in adult patients: a concise clinical review on pulmonary and extrapulmonary manifestations for healthcare physicians. Acta Biomed 91(4): e2020173.

2. Triposkiadis F, Starling RC, Xanthopoulos A, Butler J, Boudoulas H (2021) The counter regulatory axis of the lung renin-angiotensin system in severe COVID-19: pathophysiology and clinical implications. Heart Lung Circ 30(6): 786-794.

3. Wang D, Hu B, Hu C, Xinghuan Wang, Yan Zhao, et al. (2020) Clinical characteristics of 138 hospitalized patients with 2019 novel coronavirusinfected pneumonia in Wuhan, China. JAMA 323(11): 1061-1069.

4. Shi S, Qin M, Shen B, Bo Yang, Wei Gong, et al. (2020) Association of cardiac injury with mortality in hospitalized patients with COVID-19 in Wuhan, China. JAMA Cardiol 5(7): 802-810. 
5. Guo T, Fan Y, Chen M, Xinghuan Wang, Zhibing Lu, et al. (2020) Cardiovascular implications of fatal outcomes of patients with coronavirus disease 2019 (COVID-19). JAMA Cardiol 5(7): 811-818.

6. Kariyanna PT, Hossain N, Jayarangaiah A, Hossain NA, Francois JC, et al. (2020) Pharmaco-invasive Therapy for STEMI in a Patient with COVID-19: A Case Report. American journal of medical case reports 8(7): 192-196.

7. Kariyanna PT, Sutarjono B, Grewal E, Kamal Preet Singh, Lyudmila Aurora, et al. (2020) A Systematic Review of COVID-19 and Myocarditis. Am J Med Case Rep 8(9): 299-305.

ISSN: 2574-1241

DOI: 10.26717/BJSTR.2021.39.006337

Giuseppe Nasso. Biomed J Sci \& Tech Res

(C) (P) This work is licensed under Creative

Submission Link: https://biomedres.us/submit-manuscript.php
8. Hendren NS, Grodin JL, Drazner MH (2020) Unique Patterns of Cardiovascular Involvement in Coronavirus Disease-2019. J Card Fail 26(6): 466-469.

9. Holland TL, Baddour LM, Bayer AS, Hoen B, Miro JM, et al. (2016) Infective endocarditis. Nat Rev Dis Primers 2: 16059.

$\begin{array}{ll}\text { BIOMEDICAL } & \text { Assets of Publishing with us } \\ \text { RESEARCHES } & \text { - Global archiving of articles } \\ \text { - Immediate, unrestricted online access } & \text { - Rigorous Peer Review Process } \\ & \text { - Authors Retain Copyrights } \\ & \end{array}$

